\title{
HIV RNA Suppression and Immune Restoration: Can We Do Better?
}

\author{
Marilia Rita Pinzone, ${ }^{1}$ Michelino Di Rosa, ${ }^{1}$ Bruno Cacopardo, ${ }^{1}$ and Giuseppe Nunnari ${ }^{1,2}$ \\ ${ }^{1}$ Division of Infectious Diseases, Department of Clinical and Molecular Biomedicine, University of Catania, Catania 95125, Italy \\ ${ }^{2}$ Department of Microbiology and Immunology, Jefferson Medical College, Thomas Jefferson University, Philadelphia, PA 19107, USA
}

Correspondence should be addressed to Marilia Rita Pinzone, marilia.pinzone@virgilio.it

Received 15 November 2011; Revised 2 January 2012; Accepted 15 January 2012

Academic Editor: Carlo Torti

Copyright ( $) 2012$ Marilia Rita Pinzone et al. This is an open access article distributed under the Creative Commons Attribution License, which permits unrestricted use, distribution, and reproduction in any medium, provided the original work is properly cited.

HAART has significantly changed the natural history of HIV infection: patients receiving antiretrovirals are usually able to control viremia, even though not all virological responders adequately recover their CD4+ count. The reasons for poor immune restoration are only partially known and they include genetic, demographic and immunologic factors. A crucial element affecting immune recovery is immune activation, related to residual viremia; indeed, a suboptimal virological control (i.e., low levels of plasma HIV RNA) has been related with higher levels of chronic inflammation and all-cause mortality. The sources of residual viremia are not yet completely known, even though the most important one is represented by latently infected cells. Several methods, including $2-$ LTR HIV DNA and unspliced HIV RNA measurement, have been developed to estimate residual viremia and predict the outcome of antiretroviral therapy. Considering that poor immunologic responders are exposed to a higher risk of both AIDS-related and non-AIDS-related diseases, there is a need of new therapeutic strategies, including immunomodulators and drugs targeting the latent viral reservoirs, in order to face residual viremia but also to "drive" the host immunologic responses.

\section{Introduction}

The introduction of highly active antiretroviral therapy (HAART) has determined a significant reduction in morbidity and mortality of people living with human immunodeficiency virus (HIV) [1]. The majority of individuals taking HAART experience HIV RNA suppression below the detection limit of clinical assays (usually 20-50 copies HIV RNA/mL plasma) [2, 3]. However, despite suppressing viremia, HAART cannot eradicate HIV: residual low level viremia (LLV) can indeed be detected in most patients with ultrasensitive assays, because of the persistency of viral reservoirs and "sanctuary sites" not fully affected by HAART [4-7]. In addition to plasma HIV RNA, several protocols have been developed to estimate the burden of viral replication, including 2 "long terminal repeat" (LTR) HIV DNAs, a marker of recent cellular infection, and multispliced (MS) and unspliced (US) HIV RNA quantification [8]. Of note, not all virologically suppressed patients are able to recover their CD4+ T-cell count, thus representing a great concern because of the risk for opportunistic infections.

The reasons for defective immune restoration are not fully understood: reduced CD4+ T-cell recovery has been associated with older age [9-14], higher HIV RNA before HAART [10, 12, 15-19], lower baseline CD4+ count [10-12, 20-22], bone marrow [23, 24], and thymic dysfunction [2527]; genetic factors, including CCR5 polymorphism [28], some antiretroviral drugs [29-31], and immune activation [32] has also been related with impaired immune restoration.

In this paper, we first describe the mechanisms which may affect immune restoration, focusing on the role of immune activation and residual viremia. We briefly outline the main sources of LLV and the most commonly used assays to identify latently infected cells and we report the most recent evidence about the clinical implications related to LLV. We then summarize the potentialities of new therapeutic options, including immune therapy and 
"reactivation strategies," in reconstituting immune functions of HIV-infected subjects.

\section{Definition and Timing of Immune Restoration}

The increase in peripheral CD4+ $\mathrm{T}$ cells observed during HAART occurs in three distinct phases: during the first 3-6 months of HAART, the significant increase (20-30 cells $/ \mu \mathrm{L}$ monthly) in circulating naive and memory CD4+ $\mathrm{T}$ cells may be explained by the redistribution of $\mathrm{T}$ cells from the lymphoid tissues to the blood [33-35]; viral load suppression, with the subsequent decrease in immune activation, has been shown to downregulate the expression of adhesion molecules on the surface of $\mathrm{T}$ cells, such as intercellular adhesion molecule-1 (ICAM-1) and vascular cell adhesion molecule-1 (VCAM-1), which are responsible for T-cell trapping in the lymphoid organs. This mechanism results in T-cell dismissal in the blood [36]. The second phase (5-10 cells/ $\mu \mathrm{L}$ monthly, until the end of the second year of HAART) and the third phase (2-5 cells/ $\mu$ L monthly, until at least the seventh year of antiretroviral therapy) of immune restoration are due to several mechanisms, globally leading to the rise in $\mathrm{T}$ cells, especially naive ones $[10,37,38]$ : the stimulation of thymic lymphopoiesis and the proliferation of residual $\mathrm{CD} 4+\mathrm{T}$ cells are the main causes of immune restoration [39]; lifespan increase of CD4+ T cells may also account for T-cell recovery under HAART, especially in older subjects, who physiologically have a reduced thymic function [40]. Of note, these potentially compensatory responses to HIV infection do not have the same immunological meaning, considering that de novo proliferation of $\mathrm{CD} 4+\mathrm{T}$ cells may potentially restore a complete $\mathrm{T}$-cell repertoire; by contrast, the increased proliferation and survival of residual $\mathrm{CD} 4+\mathrm{T}$ cells, even if able to apparently guarantee $\mathrm{T}$-cell recovery, is not associated with a good quality of immune reconstitution, because of its inability to reconstitute a complete T-cell repertoire.

In most studies, a strong correlation between the magnitude of the change in plasma HIV RNA and the increase in circulating CD4+ T cells has been described. Le Moing et al. [37] reported a significant association between the long-term slope of CD4+ T cells and the variation of plasma HIV RNA levels when studying a large cohort of HIV-infected patients at the initiation of a protease-inhibitor- (PI-) containing antiretroviral regimen. In fact, the long-term slope was 2.5 cells $/ \mathrm{mm}^{3} /$ month higher in patients who had plasma HIV RNA levels of less than 500 copies $/ \mathrm{mL}$ at month 4 $(P<0.001)$, in comparison with those having no virological response. Nevertheless, this increase in CD4+ T-cell count was significantly attenuated after occurrence of a rebound in plasma HIV RNA > 500 copies $/ \mathrm{mL}$, thus suggesting the importance to achieve and maintain a good virological control. Pretreatment HIV RNA levels have been significantly correlated with CD4+ T-cell recovery in several studies [14, 37-39]: as previously noticed, this observation may be due to the fact that higher plasma HIV RNA levels associate with greater numbers of $\mathrm{CD} 4+\mathrm{T}$ cells being sequestered within lymphatic tissues, resulting in a greater redistribution of cells after HAART-induced viral suppression.

It is interesting to note that CD4+ T-cell recovery under HAART does not lead to the full restoration of humoral and cellular immune functions. Indeed, a number of studies have described functional impairment of both innate and acquired immune responses despite effective HAART. Chehimi et al., for instance, observed only a partial recovery of functional plasmacytoid dendritic cells (PDCs) and natural killer (NK) cells after 52 weeks of suppressive HAART [41]. In this study, patients were divided into two groups, one composed of subjects achieving rapid viral load suppression (HIV RNA < 50 copies/mL by week 12), the other composed of subjects with delayed viral suppression. Subjects with delayed viral suppression had a higher baseline viremia (29.254 copies/mL versus 4.134 copies $/ \mathrm{mL}$ ); moreover, baseline viral load was a negative predictor of PDCs recovery after 52 week of HAART ( $r=$ $-0.47, P=0.08)$. Restoration of total NK cells was incomplete even after 52 weeks on HAART when considering the whole HIV-positive cohort ( 73 cells $/ \mu \mathrm{L}$ versus 122 cells $/ \mu \mathrm{L}$ in controls). Furthermore, cytokine-induced IFN-gamma production by NK cells has been shown to be similarly impaired in asymptomatic, viremic, and HAART-suppressed HIV-positive subjects [42]. Stone et al. [43] found that CD4+ $\mathrm{T}$ cells from HIV-infected patients had increased expression of the coinhibitory protein cytotoxic T-lymphocyte antigen4 (CTLA-4) and decreased expression of the costimulatory protein $\mathrm{CD} 28$, even in presence of increased CD4+ T-cell count and great control of HIV viral load by HAART. CTLA4 and CD28 play a crucial role in T-cell activation after engagement by CD80/CD86 on antigen-presenting cells, so that their dysregulated expression on $\mathrm{T}$ cells may contribute to impaired T-cell functions.

There is not a consensus definition of immunologic nonresponder individuals: some authors described patients on HAART whose CD4+ T-cell count remained below a critical threshold, ranging between 350 and 500 cells $/ \mu \mathrm{L}$, over an extended period of time (more than 4-7 years in most studies), as poor immune responders, in which viroimmunologic dissociation implies a greater risk of AIDSrelated and non-AIDS-related illnesses [44-46]; some others analyzed immune recovery over a shorter period of time, usually 6-12 months of HAART, defining as immunologic nonresponders those patients whose CD4+ T-cell count increase was $<30 \%$ and total CD4+ T-cell count $\leq 200$ cells $/ \mu \mathrm{L}[47]$.

\section{Risk Factors for Impaired CD4+ T-Cell Recovery}

Immunologic nonresponse despite effective HAART appears to have a multifactorial origin, since a number of hostrelated and HIV-related factors contribute to a suboptimal immune reconstitution [48] (Figure 1). Some demographic characteristics, like male sex and older age, have been associated with reduced CD4+ T-cell gain: these findings may be explained by the fact that thymic output is higher 


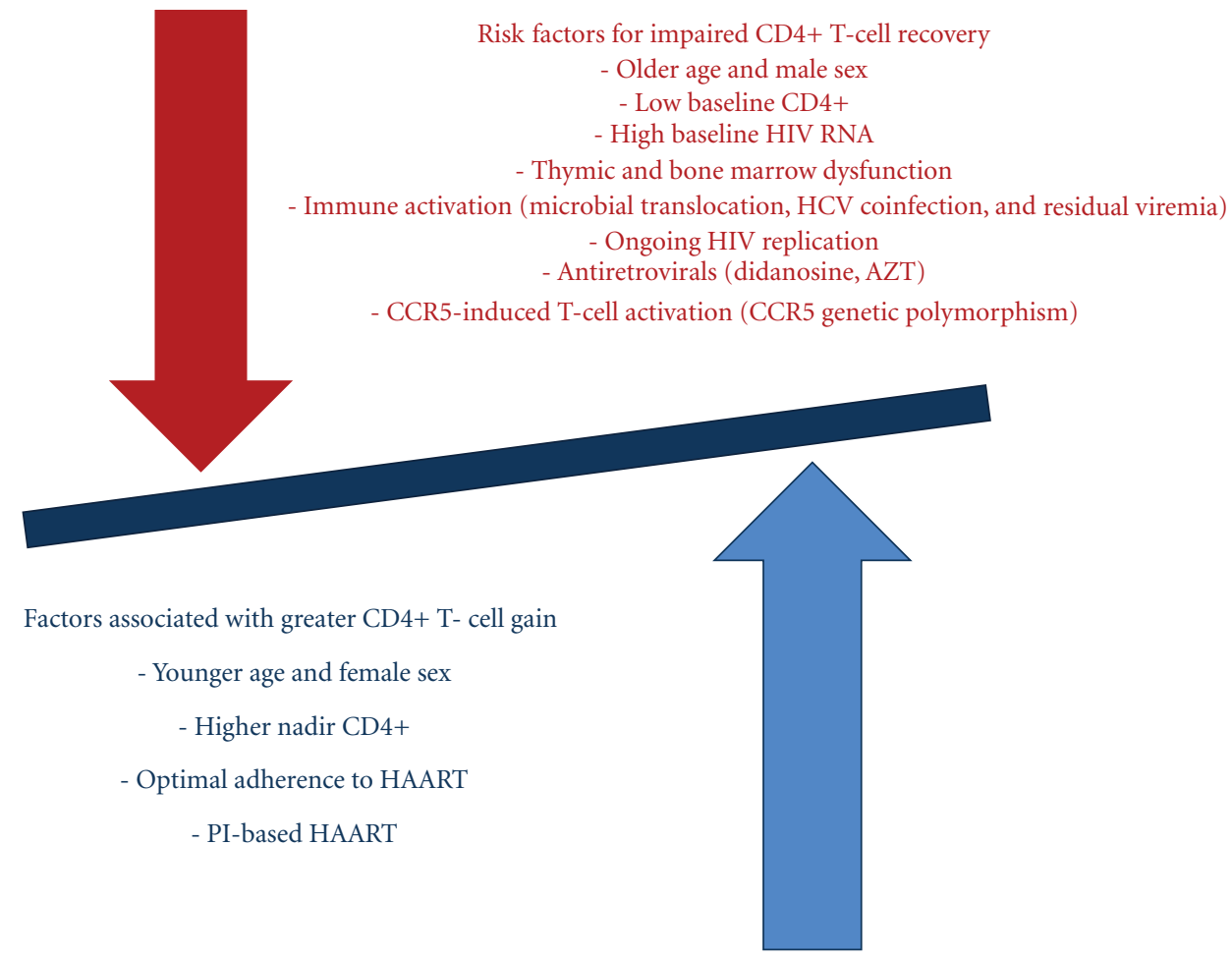

FIGURE 1: Factors affecting immune restoration in patients on HAART.

in women and younger subjects and it is closely associated with de novo production of CD4+ $\mathrm{T}$ cells [49]. In fact, impaired central regeneration of $\mathrm{T}$ cells, consistent with altered thymopoiesis, has been reported as a key determinant of poor immune reconstitution. T-cell receptor (TCR) excision circles (TRECs) have been used as a surrogate marker of thymic output, because they represent sequences of extrachromosomal DNA which are not replicated during T-cell divisions and therefore are not present in the progeny. In subjects with reduced immune restoration, a lower level of TRECs in $\mathrm{T}$ cells has been found by some authors $[50,51]$; in addition, a lower percentage of recent thymic immigrant CD4+ $\mathrm{T}$ cells (CD31+\%), has been described in immunologic nonresponders in comparison with immunologic responders [52], thus supporting, again, the contribute of thymic exhaustion to poor CD4+ gain despite suppressive HAART [25-27]. It remains to be established if it is the thymus itself to be unable to respond to thymopoietic signals, for example, IL-7, or if it is the insufficient production of thymopoietic molecules to compromise thymic-dependent immune recovery. IL-7 is a potent pleiotropic cytokine implicated in both thymopoiesis and peripheral homeostasis. IL-7 is constitutively produced by stromal cells from the bone marrow and thymus. In the thymus, it supports the viability and the expansion of early thymocytes; at the peripheral level, it costimulates $\mathrm{T}$ cells, thereby initiating their proliferation and survival. Furthermore, it has been shown to increase CD8+ T-cell cytotoxicity and to promote NK-cell functions [53]. IL-7 production is increased in lymphopenic conditions [54]. In fact, when studying a cohort of 168
HIV-positive patients, Napolitano et al. found higher IL-7 levels to be independently associated with lower CD4+ Tcell count $(P=0.0001)$ and higher plasma HIV RNA levels $(P=0.002)$. Consistent with the findings of the crosssectional study, the longitudinal analysis of a smaller cohort of 11 HIV-infected patients, observed over 6-25 months, confirmed the increase in IL-7 levels to be significantly associated with a decrease in the CD4+ T-cell count $(\rho=$ $-0.64 ; P=0.03)$ but not with changes in viral load anymore $(\rho=-0.41 ; P=0.21)$. Despite similar IL-7 plasma levels in immunologic responders and nonresponders, it has been shown that patients with poor immune recovery are characterized by reduced IL-7 receptor expression on different T-cell populations, thus potentially limiting the compensatory effect of higher IL-7 levels [55]. Female sex hormones have been shown to exert an antiapoptotic role on neutrophils [56]; it may be speculated a similar function on CD4+ T cells, which may at least partially explain the greater immune restoration found in women in comparison with men. A more direct link between T-cell recovery and gender has been recently described by Olsen and Kovacs, who demonstrated that the thymus is a target for androgen hormones, as suggested by the observation of increased thymic T-cell output in hypogonadal men [57]. The role of genetics has been emphasized by several authors: the stimulation of C-C chemokine receptor type 5 (CCR5) on CD4+ T-cell surface has been associated with T-cell activation [58]; in subjects carrying a CCR5 polymorphism, determining CD4+ T-cell activation, the polymorphism has been found to be predictive of immunologic response [28]. 
Multiple studies reported that patients receiving PI-based regimens had a better T-cell recovery [59-62], possibly because PIs may restore T-cell proliferative responses [63] and activate antiapoptotic pathways [64]. The administration of other antiretroviral drugs has been reported to have a deleterious effect on CD4+ T-cell gain: AZT, for instance, has been shown to be toxic for hematopoietic progenitors [29], didanosine to block T-cell proliferation and differentiation [30].

Immune activation is considered a key element in determining poor immune restoration [23, 32, 55, 65-67]: the immune system of HIV-infected subjects has to cope with a massive T-cell apoptosis [68, 69], which appears closely associated with the continuous stimulatory effect of proinflammatory cytokines and viral antigens [70]. The depletion of CD4+ $\mathrm{T}$ cells in mucosal lymphoid tissues is considered a key element of immune activation, because it leads to the disruption of the mucosal barrier in the gut, whose physiological function is to prevent microbial translocation from the gut to the systemic immune system [70-73]. Microbial translocation results in elevated plasma levels of bacterial 16s DNA and lipopolysaccharide (LPS) $[73,74]$, which have been directly correlated with reduced CD4+ T-cell recovery after starting HAART $[66,73,74]$. Coinfection with HCV [75-77] or Herpesviridae (EBV, $\mathrm{CMV}$ ) reactivation $[78,79]$ have also been associated with immune activation and poor CD4+ T-cell recovery.

\section{Residual Viremia, HIV Latency, and Poor Immune Restoration}

Residual viremia has been shown to trigger immune activation [48]: it is not yet well known if residual LLV represents the result of ongoing cycles of viral replication or if it is caused by the release of virus from stable HIV reservoirs [80]. As refers to the first hypothesis, some authors have recently shown that there is not evolution in HIV genome during HAART, thus implying the absence of ongoing cycles of productive viral replication. Furthermore, the characterization of rebounding virus during structured therapeutic interruptions has shown no evidence of evolution when compared with pretreatment samples [81]; analogously, some studies reported that HAART intensification with the addition of raltegravir, in patients on suppressive regimens, did not significantly decrease viremia, thus suggesting, again, the absence of ongoing cycles of replicating virus [82-85]. Further support to this observation emerged from earlier studies, showing that the level of persistent viremia was not related to treatment regimen but to pretreatment viral load; all effective HAART regimens suppressed HIV viral load to the same average level, a level that was not determined by the regimen itself, but by the size of the viral reservoirs [86]. On the other hand, some authors have reported opposing results: the presence of extrachromosomic HIV DNA, including circular DNA containing "long terminal repeat" sequences (LTR), a putative marker of recent cell infection, has been found in virologically suppressed patients [87]; likewise, an increase in the amount of 2-LTR forms of HIV DNA in the peripheral blood mononuclear cells (PBMCs) of patients under treatment intensification with raltegravir supported the idea of the persistency of ongoing replication [88].

The presence of long-lived latently infected cells is generally considered the main cause of LLV. HIV latency occurs in resting central memory $\left(\mathrm{T}_{c m}\right)$ and transitional memory $\left(\mathrm{T}_{t m}\right)$ CD4+ cells [89], but also in astrocytes [90, 91], monocyte-macrophages [92], naive T cells [93, 94], and thymocytes [95]. Latently infected cells can be detected in blood and tissues, such as the gastrointestinal tract [96], the central nervous system $[91,97]$, the genital tract [98-100], which represent "sanctuary sites", where HAART poorly penetrates. When activated, latently infected CD4+ T cells can release the virus in the blood, even if antiretrovirals are able to prevent new rounds of infection; during HAART, these cells decay very slowly, with an average half-life of 44 months, so that under current treatment it will take over 60 years to deplete this reservoir [101]. The pretreatment HIV-1 DNA level in PBMCs has been identified as a relevant marker in predicting residual viremia for patients receiving an identical HAART regimen [4], as cell-associated HIV DNA is considered a good surrogate marker of the total number of latently infected cells [102]. Quantification of cell-associated unspliced (US) and multiply spliced (MS) HIV RNA has been proposed as an helpful tool to estimate residual productively infected cells and to predict the virological outcome of therapy in patients on HAART: Pasternak et al. demonstrated that the level of HIV US RNA in PBMCs, as measured in HAART-treated patients with undetectable viremia, strongly correlated with the likelihood to experience HAART failure. In fact, median US RNA levels were significantly higher in patients who underwent HAART failure (0.43 $\log _{10}$ difference, $\left.P=0.0015\right)$ in comparison with those who remained virologically suppressed and inversely correlated with baseline CD4+ T-cell count; furthermore, in multivariate analysis, after adjusting for baseline CD4+ Tcell count, prior HAART experience and particular HAART regimens, the maximal US RNA level under therapy was the best independent predictor of subsequent therapy failure (adjusted odds ratio [95\% CI], 24.4 [1.5-389.5], $P=0.024$ ) [103].

Several studies have shown that the persistency of residual viremia represents a continuous proinflammatory stimulus for the immune system, causing immune activation and chronic inflammation. Of interest, a recent work of d'Ettorre et al. [104] has found out the association of HIV persistence in the gut mucosa of HAART-treated subjects with immune activation and microbial translocation: in fact, the level of HIV DNA in the gut correlated with plasma level of LPS and with the levels of expression of the activation marker CD38 on CD8+ T cells. In the SMART trial, levels of C-reactive protein (CRP), Interleukin (IL)-6, and D-Dimer remained elevated in HIV-infected subjects, despite suppressive HAART [105]; furthermore, IL6 and D-Dimer were strongly associated with mortality, even in patients achieving viral suppression [106]. Contrasting results were recently published by Eastburn et al. [107]. The authors explored the association of LLV with inflammation, increased coagulation, and all-cause mortality and they 
unexpectedly found little association of LLV with CRP, IL6 and fibrinogen: in fact, CRP levels did not correlate with HIV viral load, while increasing HIV RNA was associated with higher IL-6 and fibrinogen levels, but only for subjects whose viral load was above 10.000 copies $/ \mathrm{mL}$. As refers to IL6 , this association was attenuated by $\sim 50 \%$ after adjusting for CD4+ T-cell count. In addition, HIV RNA was not associated with mortality risk over 5 years, after adjustment for CD4+ T-cell count, cardiovascular risk factors, and inflammation. These contrasting data suggest the need for more studies, properly designed to identify the most reliable coagulopathic/inflammatory markers associated with HIV ongoing replication/persistence and to further explore whether LLV predisposes to increased inflammation and allcause mortality. Furthermore, in addition to cross-sectional plasma HIV RNA measures, some authors have investigated the use of other biomarkers, which may be able to better describe the patient longitudinal exposure to HIV burden and to potentially work as a proxy measure of cumulative inflammation and immune system activation [108, 109]. Mugavero et al. have recently proposed viremia copy-years, a time-varying measure of cumulative plasma HIV exposure, as an independent predictor of mortality, even after adjusting for most recent CD4+ T-cell count, thus substantiating the role of HIV replication in accelerating disease progression, independently of its effects on peripheral CD4+ T-cell depletion [108].

\section{Potential Strategies to Reduce Residual Viremia and Enhance Immune Restoration}

Considering that functional and numerical normalization of CD4+ T-cells appears to be fundamental to prevent both AIDS-related and non-AIDS-related morbidity and mortality, there is a need of new therapeutic strategies for immunologic nonresponder patients (Figure 2).

We have previously highlighted the crucial role of immune activation in causing poor $\mathrm{CD} 4+\mathrm{T}$-cell gain in patients receiving HAART; therefore, strategies aiming at reducing immune activation would be worthy to enhance immune restoration. An attempt to suppress polyclonal T-cell activation has been made by some authors using immunosuppressive drugs, such as hydroxyurea, corticosteroids, cyclosporine A, mycophenolate, with no effective results, even considering that immunosuppressive adverse effects may overwhelm the theoretical benefits of reduced T-cell activation [110]. More encouraging results have been associated with the use of maraviroc, a CCR5 antagonist, which has been shown to reduce the levels of activated CD4+ and CD8+ T cells $[111,112]$ and to induce a greater increase in $\mathrm{CD} 4+\mathrm{T}$-cell count in treatment naive patients at week 48 and 96 , in comparison with efavirenz [113]. The anti-inflammatory and immunomodulatory functions of statins have recently been evaluated by De Wit et al., who have shown atorvastatin to significantly reduce the level of immune activation, measured by CD8+/CD38+ percentage, but not to affect highly sensitive CRP levels or CD4+ T-cell response in HAART-suppressed

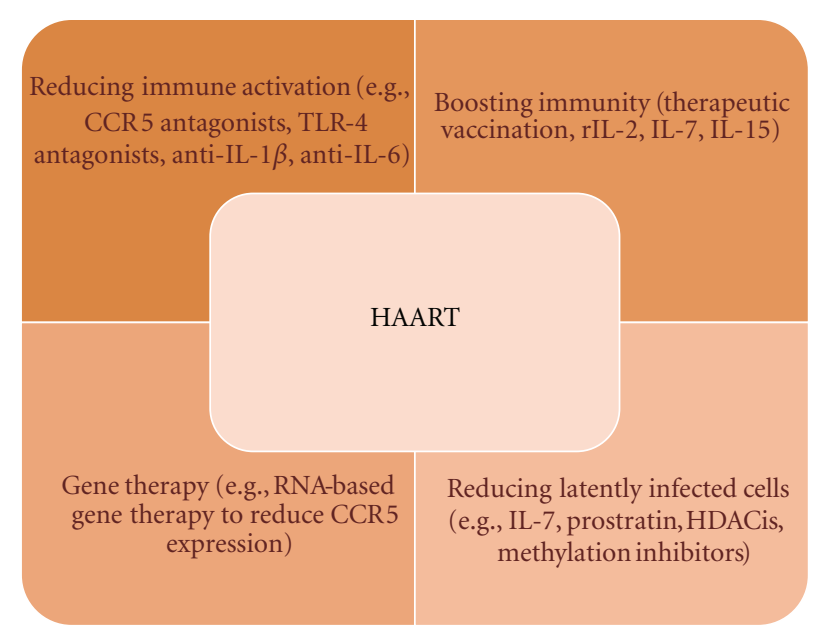

FIGURE 2: Therapeutic options for increasing CD4+ T-cell recovery. HAART obviously remains the milestone of any treatment; in addition, other potential strategies, targeting some aspects associated with poor immune restoration, are here reported.

patients [114]. As refers to microbial translocation, the use of probiotics has been suggested to favorably modify the balance between "good" and "bad" intestinal flora; furthermore, the use of inhibitors of bacterial productmediated effects (antagonists of toll like receptor- 4 , the receptor for LPS [115]) or inhibitors of proinflammatory cytokines (anti-IL-1 $\beta$, anti-IL-6 or antitumor necrosis factor (TNF)- $\alpha[116])$ is another option currently under evaluation. The antiviral and anti-inflammatory properties of the antimalarial drug hydroxychloroquine (HCQ) have recently been analyzed in a cohort of 20 HAART-treated immunologic nonresponders by Piconi et al. [117], who studied the impact of HCQ ( $400 \mathrm{mg} /$ day for 6 months) on immune activation: HCQ significantly reduced plasma LPS, LPS/TLR-mediated signal transduction and IL-6/TNF- $\alpha$ production; furthermore, it increased percentages of circulating CD4+ T cells. These effects were mostly retained two months after therapy interruption. However, a trend, but not a significant increase in CD4+ T-cell count was observed, thus indicating that more studies are needed to check the immunomodulating potentialities of HCQ. Some clinical trials are currently in progress (ACTG A5258, http://clinicaltrials.gov/ct2/show/NCT00819390; CTN246, http://www .hivnet.ubc.ca/clinical-studies/canadian-hiv-trials-database/ ctn-246/).

Strategies to restore the regenerative capacity of immune system include the administration of recombinant interleukin-2 (rIL-2) and IL-7. Endogenous IL-2 is produced by activated $\mathrm{CD} 4+\mathrm{T}$ cells and it is important for antigen processing and induction of CD8+ T-cell cytotoxic activity; in HIV-positive subjects, IL-2 levels are lower, so that CD8+ cytotoxicity is impaired and the virus may easily escape from the host immune system. Some clinical trials demonstrated the efficacy of one year-treatment with rIL2 plus HAART versus HAART alone in determining CD4+ T-cell gain $[118,119]$; furthermore, the benefits of rIL-2 
administration in terms of CD4+ count were maintained for over 95 months in another follow up study [120]. First, rIL2 administration may help facing CD4+ T-cell loss, mainly through the expansion of the naive CD4+ compartment; it does not seem to be a mere matter of quantity but also of quality: in fact, there was not only a numerical increase but also a significant rise in functionally competent CD4+ CD28+ T cells, being CD28 a costimulatory molecule, whose expression is needed for antigenic presentation [121, 122]. In addition, rIL-2 may promote the proliferation of CD8+ $\mathrm{T}$ cells [123] and inhibit HIV replication in macrophages [124]. Despite the significant increase in CD4+ T-cell count, the ESPRIT and SILCAAT study, two recent prospective, randomized, controlled, phase III studies exploring the clinical benefits of intermittent subcutaneous rIL-2 with HAART versus HAART alone, have shown no significant differences in HIV RNA levels and no clinical benefits to the patients in the rIL-2 arm $[125,126]$. As refers to IL7 , a recent trial has demonstrated a sustained increase in $\mathrm{T}$ cells after administration of recombinant human (rh) IL-7 to HIV-infected patients [127], because of both increase in thymopoiesis as well as a direct increase in the magnitude of antigen-driven peripheral T-cell expansion [128].

Another potential immunomodulatory strategy is associated with NK-cell capability to exert a direct cytotoxic effect and to produce soluble factors able to control HIV replication [129]. From this perspective, some authors have evaluated the immunological effects of IL-15, a pleiotropic cytokine which is involved in NK-cell proliferation and survival [130]. D'Ettorre et al. have recently reported that the in vitro challenging of NK cells with IL-15 was able to significantly reduce the level of viral p24 antigen in cocultured infected CD4+ T cells and PBMCs media. Furthermore, IL15 stimulated NK cells reduced HIV DNA viral load both in purified CD4+ T cells and PBMCs [131]. In a previous study of the same group, IL-15 priming was shown to induce a significant increase of IFN-gamma production in both viremic and aviremic HIV-positive patients [132]. Tarkowski et al. [133] found that the expression of IL-15, but not of its receptor IL-15R $\alpha$, was significantly higher in the CD14+ monocytes of long-term nonprogressors than in those of HIV-1 progressors or healthy controls; differences in IL-15 expression between patients with different courses of HIV infection may be indicative of a potential use of this cytokine as a therapeutic agent.

Many strategies have been explored to eradicate residual viremia in subjects on HAART: latently infected cells do not differ from uninfected cells, apart from the presence of integrated HIV DNA but, when activated, these cells may become vulnerable to immune-mediated killing and to antiretrovirals, so that a current "hot topic" is focused on reactivating latently infected cells, in order to induce integrated HIV expression; for example, IL-7 has been shown to induce productive infection from latently infected CD4+ $\mathrm{T}$ cells in vitro, through the activation of the Jak-Stat pathway $[127,134,135]$ and it is currently ongoing clinical trials, to determine if it may be effective to reduce in vivo latent reservoirs (ERAMUNE, http://www.clinicaltrials.gov). It has been recently shown that the stimulation of CD $4+\mathrm{T}$ cells from viremic donors with IL-7 or IL-15 was able to induce in both cases viral production in productively infected cells, even if these cytokines showed a different impact on the maintenance of latently infected CD4+ T cells: in fact, IL7 had a major effect on homeostatic proliferation of cells harboring integrated HIV DNA, whereas IL-15 promoted the differentiation of $\mathrm{T}_{\mathrm{cm}} \mathrm{CD} 4+\mathrm{T}$ cells and increased the percentage of short-lived effector memory $\left(\mathrm{T}_{e m}\right) \mathrm{T}$ cells [136].

The upregulation of cellular transcription has been suggested as another strategy to induce HIV genome expression and reverse latency, for instance by promoting histone acetylation [137]. Histone deacetylase inhibitors (HDACis), such as valproic acid, sodium butyrate, and suberoylanilide hydroxamic acid (SAHA), have been shown to enhance cellular transcription, including HIV LTR [138]; however, some retrospective studies failed to demonstrate a significant reduction of latent reservoirs when administering valproic acid [139-141]. Due to the fact that active nuclear factorkappa $\mathrm{B}(\mathrm{NF}-\kappa \mathrm{B})$ is a positive regulator of HIV expression, the use of the NF- $\kappa \mathrm{B}$ activator prostratin, in combination with HDACis, has been shown to enhance HIV transcription in vitro $[142,143]$. Mehla et al. have recently reported the in vitro capability of bryostatin, a Protein Kinase C (PKC) agonist, to reactivate latent viral infection in monocytic and lymphocytic cells, mainly because of PKC-induced activation of NF- $\kappa$ B [144]. In addition, considering that DNA methylation prevents HIV expression, the use of methylation inhibitors, such as decitabine, has been proposed to eliminate HIV from latently infected resting CD4+ T cells [145, 146]. Anyhow, the in vitro efficacy of these families of compounds needs to be tested first in animal models and then in well-designed and well-tolerated clinical trials, to understand if the "reactivation strategy" may also work in vivo.

Recently, it has been suggested that compounds able to promote the differentiation of the long-lived $T_{\mathrm{cm}}$ and $\mathrm{T}_{\mathrm{tm}}$ CD4+ T cells, which play a main role in HIV persistence [89], into $\mathrm{T}_{\mathrm{em}}$-like phenotypes, may contribute to the restriction of the viral reservoir. The gold-based compound auranofin, which acts through the induction of reactive oxygen species, has been shown to accelerate CD4+ T-cell turnover, thus inducing long-lived memory cells to progress to short-lived phenotypes and die [147].

Finally, therapeutic vaccination has been evaluated over the last years, with mixed results, as a strategy aiming at boosting immunity to HIV, generating HIV-specific CD4+ and CD8+ T-cell responses, possibly able to control viral replication and enhance immune recovery [148, 149].

\section{Conclusions}

HAART has profoundly changed the natural history of HIV infection, but a good suppression of HIV does not mean viral elimination. We are still looking for therapeutic approaches able to eradicate the virus; the persistency of latently infected cells and latent reservoirs represents indeed a major challenge for the virologists and clinicians, considering that residual 
LLV works as a trigger for immune activation and increased T-cell apoptosis.

Furthermore, not all virologically suppressed patients are able to effectively recover their CD4+ T-cell count, thus exposing immunologic nonresponders to a significant risk of both AIDS-related and non-AIDS-related morbidities. Despite the ever-growing number of new available antiretrovirals, giving us new "weapons" to control viremia, the approach to patients with poor immune recovery is challenging; immune modulation, together with drugs targeting the latent reservoirs, appear the most encouraging options. Further studies are needed to better understand the mechanisms that influence immune restoration and to validate in vivo the evidence coming from in vitro studies.

\section{References}

[1] F. J. Palella, K. M. Delaney, A. C. Moorman et al., "Declining morbidity and mortality among patients with advanced human immunodeficiency virus infection," The New England Journal of Medicine, vol. 338, no. 13, pp. 853-860, 1998.

[2] S. M. Hammer, K. E. Squires, M. D. Hughes et al., "A controlled trial of two nucleoside analogues plus indinavir in persons with human immunodeficiency virus infection and CD4 cell counts of 200 per cubic millimeter or less," The New England Journal of Medicine, vol. 337, no. 11, pp. 725-733, 1997.

[3] R. M. Gulick, J. W. Mellors, D. Havlir et al., "Treatment with indinavir, zidovudine, and lamivudine in adults with human immunodeficiency virus infection and prior antiretroviral therapy," The New England Journal of Medicine, vol. 337, no. 11, pp. 734-739, 1997.

[4] D. V. Havlir, K. K. Koelsch, M. C. Strain et al., "Predictors of residual viremia in HIV-infected patients successfully treated with efavirenz and lamivudine plus either tenofovir or stavudine," Journal of Infectious Diseases, vol. 191, no. 7, pp. 1164-1168, 2005.

[5] S. Palmer, A. P. Wiegand, F. Maldarelli et al., "New realtime reverse transcriptase-initiated PCR assay with singlecopy sensitivity for human immunodeficiency virus type 1 RNA in plasma," Journal of Clinical Microbiology, vol. 41, no. 10, pp. 4531-4536, 2003.

[6] S. Palmer, F. Maldarelli, A. Wiegand et al., "Low-level viremia persists for at least 7 years in patients on suppressive antiretroviral therapy," Proceedings of the National Academy of Sciences of the United States of America, vol. 105, no. 10, pp. 3879-3884, 2008.

[7] G. Dornadula, H. Zhang, B. VanUitert et al., "Residual HIV1 RNA in blood plasma of patients taking suppressive highly active antiretroviral therapy," JAMA, vol. 282, no. 17, pp. 1627-1632, 1999.

[8] S. R. Lewin and C. Rouzioux, "HIV cure and eradication: how will we get from the laboratory to effective clinical trials?" AIDS, vol. 25, no. 7, pp. 885-897, 2011.

[9] C. F. Kelley, C. M. R. Kitchen, P. W. Hunt et al., "Incomplete peripheral $\mathrm{CD}^{+}$cell count restoration in HIV-infected patients receiving long-term antiretroviral treatment," Clinical Infectious Diseases, vol. 48, no. 6, pp. 787-794, 2009.

[10] G. R. Kaufmann, L. Perrin, G. Pantaleo et al., "CD4 Tlymphocyte recovery in individuals with advanced HIV-1 infection receiving potent antiretroviral therapy for 4 years: the Swiss HIV cohort study," Archives of Internal Medicine, vol. 163, no. 18, pp. 2187-2195, 2003.

[11] G. R. Kaufmann, M. Bloch, R. Finlayson, J. Zaunders, D. Smith, and D. A. Cooper, "The extent of HIV-1-related immunodeficiency and age predict the long-term CD4 T lymphocyte response to potent antiretroviral therapy," AIDS, vol. 16, no. 3, pp. 359-367, 2002.

[12] R. D. Moore and J. C. Keruly, "CD4+ cell count 6 years after commencement of highly active antiretroviral therapy in persons with sustained virologic suppression," Clinical Infectious Diseases, vol. 44, no. 3, pp. 441-446, 2007.

[13] K. N. Althoff, A. C. Justice, S. J. Gange et al., "Virologic and immunologic response to HAART, by age and regimen class," AIDS, vol. 24, no. 16, pp. 2469-2479, 2010.

[14] J. P. Viard, A. Mocroft, A. Chiesi et al., "Influence of age on CD4 cell recovery in human immunodeficiency virus-infected patients receiving highly active antiretroviral therapy: evidence from the EuroSIDA study," Journal of Infectious Diseases, vol. 183, no. 8, pp. 1290-1294, 2001.

[15] P. M. Tarwater, J. B. Margolick, J. Jin et al., "Increase and plateau of CD4 T-cell counts in the $31 / 2$ years after initiation of potent antiretroviral therapy," Journal of Acquired Immune Deficiency Syndromes, vol. 27, no. 2, pp. 168-175, 2001.

[16] G. R. Kaufmann, H. Furrer, B. Ledergerber et al., "Characteristics, determinants, and clinical relevance of CD4 T cell recovery to $<500$ cells $/ \mu \mathrm{L}$ in HIV type 1-infected individuals receiving potent antiretroviral therapy," Clinical Infectious Diseases, vol. 41, no. 3, pp. 361-372, 2005.

[17] S. Egger, K. Petoumenos, A. Kamarulzaman et al., "Longterm patterns in CD4 response are determined by an interaction between baseline CD4 cell count, viral load, and time: the asia pacific HIV observational database (APHOD)," Journal of Acquired Immune Deficiency Syndromes, vol. 50, no. 5, pp. 513-520, 2009.

[18] E. Florence, J. Lundgren, C. Dreezen et al., "Factors associated with a reduced CD4 lymphocyte count response to HAART despite full viral suppression in the EuroSIDA study," HIV Medicine, vol. 4, no. 3, pp. 255-262, 2003.

[19] A. Castagna, L. Galli, C. Torti et al., "Predicting the magnitude of short-term $\mathrm{CD} 4^{+} \mathrm{T}$-cell recovery in HIV-infected patients during first-line highly active antiretroviral therapy," Antiviral Therapy, vol. 15, no. 2, pp. 165-175, 2010.

[20] C. J. Smith, C. A. Sabin, M. S. Youle et al., "Factors influencing increases in CD4 cell counts of HIV-positive persons receiving long-term highly active antiretroviral therapy," Journal of Infectious Diseases, vol. 190, no. 10, pp. 1860-1868, 2004.

[21] P. W. Hunt, S. G. Deeks, B. Rodriguez et al., "Continued CD4 cell count increases in HIV-infected adults experiencing 4 years of viral suppression on antiretroviral therapy," AIDS, vol. 17, no. 13, pp. 1907-1915, 2003.

[22] K. Falster, K. Petoumenos, J. Chuah et al., "Poor baseline immune function predicts an incomplete immune response to combination antiretroviral treatment despite sustained viral suppression," Journal of Acquired Immune Deficiency Syndromes, vol. 50, no. 3, pp. 307-313, 2009.

[23] A. Isgrò, W. Leti, W. De Santis et al., "Altered clonogenic capability and stromal cell function characterize bone marrow of HIV-infected subjects with low $\mathrm{CD} 4^{+} \mathrm{T}$ cell counts despite viral suppression during HAART," Clinical Infectious Diseases, vol. 46, no. 12, pp. 1902-1910, 2008. 
[24] J. Kulkosky, M. Bouhamdan, A. Geist, G. Nunnari, D. G. Phinney, and R. J. Pomerantz, "Pathogenesis of HIV-1 infection within bone marrow cells," Leukemia and Lymphoma, vol. 37, no. 5-6, pp. 497-515, 2000.

[25] E. Ruiz-Mateos, A. Rubio, A. Vallejo et al., "Thymic volume is associated independently with the magnitude of shortand long-term repopulation of $\mathrm{CD} 4^{+} \mathrm{T}$ cells in HIV-infected adults after highly active antiretroviral therapy (HAART)," Clinical and Experimental Immunology, vol. 136, no. 3, pp. 501-506, 2004.

[26] K. Y. Smith, H. Valdez, A. Landay et al., "Thymic size and lymphocyte restoration in patients with human immunodeficiency virus infection after 48 weeks of zidovudine, lamivudine, and ritonavir therapy," Journal of Infectious Diseases, vol. 181, no. 1, pp. 141-147, 2000.

[27] L. Teixeira, H. Valdez, J. M. McCune et al., "Poor CD4 T cell restoration after suppression of HIV-1 replication may reflect lower thymic function," AIDS, vol. 15, no. 14, pp. 1749-1756, 2001.

[28] S. K. Ahuja, H. Kulkarni, G. Catano et al., "CCL3L1-CCR5 genotype influences durability of immune recovery during antiretroviral therapy of HIV-1-infected individuals," Nature Medicine, vol. 14, no. 4, pp. 413-420, 2008.

[29] D. L. Du, D. A. Volpe, C. K. Grieshaber, and M. J. Murphy, "In vitro toxicity of 3'-azido-3'-deoxythymidine, carbovir and $2^{\prime}, 3^{\prime}$-dihydro-2', $3^{\prime}$-dideoxythymidine to human and murine haematopoietic progenitor cells," British Journal of Haematology, vol. 80, no. 4, pp. 437-445, 1992.

[30] U. Karrer, B. Ledergerber, H. Furrer et al., "Dose-dependent influence of didanosine on immune recovery in HIV-infected patients treated with tenofovir," AIDS, vol. 19, no. 17, pp. 1987-1994, 2005.

[31] M. Viora, G. Di Genova, R. Rivabene, W. Malorni, and A. Fattorossi, "Interference with cell cycle progression and induction of apoptosis by dideoxynucleoside analogs," International Journal of Immunopharmacology, vol. 19, no. 6, pp. 311-321, 1997.

[32] S. Piconi, D. Trabattoni, A. Gori et al., "Immune activation, apoptosis, and treg activity are associated with persistently reduced $\mathrm{CD}^{+}$T-cell counts during antiretroviral therapy," AIDS, vol. 24, no. 13, pp. 1991-2000, 2010.

[33] M. M. Lederman, E. Connick, A. Landay et al., "Immunologic responses associated with 12 weeks of combination antiretroviral therapy consisting of Zidovudine, Lamivudine, and Ritonavir: results of AIDS clinical trials group protocol 315," Journal of Infectious Diseases, vol. 178, no. 1, pp. 70-79, 1998.

[34] A. Guihot, R. Tubiana, G. Breton et al., "Immune and virological benefits of 10 years of permanent viral control with antiretroviral therapy," AIDS, vol. 24, no. 4, pp. 614$617,2010$.

[35] B. Ledergerber, J. D. Lundgren, A. S. Walker et al., "Predictors of trend in CD4-positive T-cell count and mortality among HIV-1-infected individuals with virological failure to all three antiretroviral drug classes," The Lancet, vol. 364, no. 9428, pp. 51-62, 2004.

[36] R. P. Bucy, R. D. Hockett, C. A. Derdeyn et al., "Initial increase in blood $\mathrm{CD}^{+}$lymphocytes after HIV antiretroviral therapy reflects redistribution from lymphoid tissues," The Journal of Clinical Investigation, vol. 103, no. 10, pp. 13911398, 1999.
[37] V. Le Moing, R. Thiébaut, G. Chêne et al., "Predictors of long-term increase in $\mathrm{CD}^{+}$cell counts in human immunodeficiency virus - infected patients receiving a protease inhibitor-containing antiretroviral regimen," Journal of Infectious Diseases, vol. 185, no. 4, pp. 471-480, 2002.

[38] J. J. Lok, R. J. Bosch, C. A. Benson et al., "Long-term increase in $\mathrm{CD}^{+}$T-cell counts during combination antiretroviral therapy for HIV-1 infection," AIDS, vol. 24, no. 12, pp. 18671876, 2010.

[39] M. M. Lederman, R. McKinnis, D. Kelleher et al., "Cellular restoration in HIV infected persons treated with abacavir and a protease inhibitor: age inversely predicts naive CD4 cell count increase," AIDS, vol. 14, no. 17, pp. 2635-2642, 2000.

[40] H. Tsukamoto, K. Clise-Dwyer, G. E. Huston et al., "Ageassociated increase in lifespan of naïve CD4 T cells contributes to T-cell homeostasis but facilitates development of functional defects," Proceedings of the National Academy of Sciences of the United States of America, vol. 106, no. 43, pp. 18333-18338, 2009.

[41] J. Chehimi, L. Azzoni, M. Farabaugh et al., "Baseline viral load and immune activation determine the extent of reconstitution of innate immune effectors in HIV-1-infected subjects undergoing antiretroviral treatment," Journal of Immunology, vol. 179, no. 4, pp. 2642-2650, 2007.

[42] L. Azzoni, E. Papasavvas, J. Chehimi et al., "Sustained impairment of IFN- $\gamma$ secretion in suppressed HIV-infected patients despite mature NK cell recovery: evidence for a defective reconstitution of innate immunity," Journal of Immunology, vol. 168, no. 11, pp. 5764-5770, 2002.

[43] S. F. Stone, P. Price, and M. A. French, "Dysregulation of CD28 and CTLA- 4 expression by CD4 T cells from previously immunodeficient HIV-infected patients with sustained virological responses to highly active antiretroviral therapy," HIV Medicine, vol. 6, no. 4, pp. 278-283, 2005.

[44] J. V. Baker, G. Peng, J. Rapkin et al., "CD4+ count and risk of non-AIDS diseases following initial treatment for HIV infection," AIDS, vol. 22, no. 7, pp. 841-848, 2008.

[45] J. V. Baker, G. Peng, J. Rapkin et al., "Poor initial CD4 ${ }^{+}$recovery with antiretroviral therapy prolongs immune depletion and increases risk for AIDS and non-AIDS diseases," Journal of Acquired Immune Deficiency Syndromes, vol. 48, no. 5, pp. 541-546, 2008.

[46] J. Reekie, C. Kosa, F. Engsig et al., "Relationship between current level of immunodeficiency and non-acquired immunodeficiency syndrome-defining malignancies," Cancer, vol. 116, no. 22, pp. 5306-5315, 2010.

[47] L. Gazzola, C. Tincati, G. M. Bellistrì, A. D. Monforte, and G. Marchetti, "The absence of $\mathrm{CD} 4^{+} \mathrm{T}$ cell count recovery despite receipt of virologically suppressive highly active antiretroviral therapy: clinical risk, immunological gaps, and therapeutic options," Clinical Infectious Diseases, vol. 48, no. 3, pp. 328-337, 2009.

[48] P. Corbeau and J. Reynes, "Immune reconstitution under antiretroviral therapy: the new challenge in HIV-1 infection," Blood, vol. 117, no. 21, pp. 5582-5590, 2011.

[49] J. Pido-Lopez, N. Imami, and R. Aspinall, "Both age and gender affect thymic output: more recent thymic migrants in females than males as they age," Clinical and Experimental Immunology, vol. 125, no. 3, pp. 409-413, 2001.

[50] O. Benveniste, A. Flahault, F. Rollot et al., "Mechanisms involved in the low-level regeneration of $\mathrm{CD}^{+}$cells in HIV-1-infected patients receiving highly active antiretroviral 
therapy who have prolonged undetectable plasma viral loads," Journal of Infectious Diseases, vol. 191, no. 10, pp. 1670-1679, 2005.

[51] C. Torti, G. Cologni, M. C. Uccelli et al., "Immune correlates of virological response in HIV-positive patients after highly active antiretroviral therapy (HAART)," Viral Immunology, vol. 17, no. 2, pp. 279-286, 2004.

[52] T. Li, N. Wu, Y. Dai et al., "Reduced thymic output is a major mechanism of immune reconstitution failure in HIV-infected patients after long-term antiretroviral therapy," Clinical Infectious Diseases, vol. 53, no. 9, pp. 944-951, 2011.

[53] S. Beq, J. F. Delfraissy, and J. Theze, "Interleukin-7 (IL7): immune function, involvement in the pathogenesis of HIV infection and therapeutic potential," European Cytokine Network, vol. 15, no. 4, pp. 279-289, 2004.

[54] L. A. Napolitano, R. M. Grant, S. G. Deeks et al., "Increased production of IL-7 accompanies HIV-1-mediated T-cell depletion: implications for T-cell homeostasis," Nature Medicine, vol. 7, no. 1, pp. 73-79, 2001.

[55] M. Marziali, W. De Santis, R. Carello et al., "T-cell homeostasis alteration in HIV-1 infected subjects with low CD4 T-cell count despite undetectable virus load during HAART," AIDS, vol. 20, no. 16, pp. 2033-2041, 2006.

[56] E. J. Molloy, A. J. O’Neill, J. J. Grantham et al., "Sex-specific alterations in neutrophil apoptosis: the role of estradiol and progesterone,” Blood, vol. 102, no. 7, pp. 2653-2659, 2003.

[57] N. J. Olsen and W. J. Kovacs, "Evidence that androgens modulate human thymic T cell output," Journal of Investigative Medicine, vol. 59, no. 1, pp. 32-35, 2011.

[58] J. F. Camargo, M. P. Quinones, S. Mummidi et al., "CCR5 expression levels influence NFAT translocation, IL-2 production, and subsequent signaling events during T lymphocyte activation," Journal of Immunology, vol. 182, no. 1, pp. 171182, 2009.

[59] R. D. MacArthur, R. M. Novak, G. Peng et al., "A comparison of three highly active antiretroviral treatment strategies consisting of non-nucleoside reverse transcriptase inhibitors, protease inhibitors, or both in the presence of nucleoside reverse transcriptase inhibitors as initial therapy (CPCRA 058 FIRST Study): a long-term randomised trial," The Lancet, vol. 368, no. 9553, pp. 2125-2135, 2006.

[60] C. Torti, F. Maggiolo, A. Patroni et al., "Exploratory analysis for the evaluation of lopinavir/ritonavir-versus efavirenzbased HAART regimens in antiretroviral-naive HIV-positive patients: results from the Italian MASTER Cohort," Journal of Antimicrobial Chemotherapy, vol. 56, no. 1, pp. 190-195, 2005.

[61] S. A. Riddler, R. Haubrich, A. G. DiRienzo et al., "Classsparing regimens for initial treatment of HIV-1 infection," The New England Journal of Medicine, vol. 358, no. 20, pp. 2095-2106, 2008.

[62] J. A. Bartlett, M. J. Fath, R. DeMasi et al., "An updated systematic overview of triple combination therapy in antiretroviral-naive HIV-infected adults," AIDS, vol. 20, no. 16, pp. 2051-2064, 2006.

[63] W. Lu and J. M. Andrieu, "HIV protease inhibitors restore impaired T-cell proliferative response in vivo and in vitro: a viral-suppression-independent mechanism," Blood, vol. 96, no. 1, pp. 250-258, 2000.

[64] E. M. Sloand, P. N. Kumar, S. Kim, A. Chaudhuri, F. F. Weichold, and N. S. Young, "Human immunodeficiency virus type 1 protease inhibitor modulates activation of peripheral blood $\mathrm{CD}^{+} \mathrm{T}$ cells and decreases their susceptibility to apoptosis in vitro and in vivo," Blood, vol. 94, no. 3, pp. 10211027, 1999.

[65] R. T. Gandhi, J. Spritzler, E. Chan et al., "Effect of baselineand treatment-related factors on immunologic recovery after initiation of antiretroviral therapy in HIV-1-positive subjects: results from ACTG 384," Journal of Acquired Immune Deficiency Syndromes, vol. 42, no. 4, pp. 426-434, 2006.

[66] G. Marchetti, G. M. Bellistrì, E. Borghi et al., "Microbial translocation is associated with sustained failure in $\mathrm{CD} 4^{+}$ T-cell reconstitution in HIV-infected patients on long-term highly active antiretroviral therapy," AIDS, vol. 22, no. 15, pp. 2035-2044, 2008.

[67] S. R. Ostrowski, T. L. Katzenstein, P. T. Thim, B. K. Pedersen, J. Gerstoft, and H. Ullum, "Low-level viremia and proviral DNA impede immune reconstitution in HIV-1-infected patients receiving highly active antiretroviral therapy," Journal of Infectious Diseases, vol. 191, no. 3, pp. 348-357, 2005.

[68] M. Massanella, E. Negredo, N. Pérez-Álvarez et al., "CD4 Tcell hyperactivation and susceptibility to cell death determine poor CD4 T-cell recovery during suppressive HAART," AIDS, vol. 24, no. 7, pp. 959-968, 2010.

[69] E. Negredo, M. Massanella, J. Puig et al., "Nadir CD4 $\mathrm{T}$ cell count as predictor and high CD4 $\mathrm{T}$ cell intrinsic apoptosis as final mechanism of poor CD4 $\mathrm{T}$ cell recovery in virologically suppressed HIV-infected patients: clinical implications," Clinical Infectious Diseases, vol. 50, no. 9, pp. 1300-1308, 2010.

[70] V. Appay and D. Sauce, "Immune activation and inflammation in HIV-1 infection: causes and consequences," Journal of Pathology, vol. 214, no. 2, pp. 231-241, 2008.

[71] M. Paiardini, I. Frank, I. Pandrea, C. Apetrei, and G. Silvestri, "Mucosal immune dysfunction in AIDS pathogenesis," AIDS Reviews, vol. 10, no. 1, pp. 36-46, 2008.

[72] J. M. Brenchley, T. W. Schacker, L. E. Ruff et al., "CD4 ${ }^{+}$T cell depletion during all stages of HIV disease occurs predominantly in the gastrointestinal tract," Journal of Experimental Medicine, vol. 200, no. 6, pp. 749-759, 2004.

[73] J. M. Brenchley, D. A. Price, T. W. Schacker et al., "Microbial translocation is a cause of systemic immune activation in chronic HIV infection," Nature Medicine, vol. 12, no. 12, pp. 1365-1371, 2006.

[74] W. Jiang, M. M. Lederman, P. Hunt et al., "Plasma levels of bacterial DNA correlate with immune activation and the magnitude of immune restoration in persons with antiretroviral-treated HIV infection," Journal of Infectious Diseases, vol. 199, no. 8, pp. 1177-1185, 2009.

[75] V. D. Gonzalez, K. Falconer, K. G. Blom et al., "High levels of chronic immune activation in the T-cell compartments of patients coinfected with hepatitis C virus and human immunodeficiency virus type 1 and on highly active antiretroviral therapy are reverted by alpha interferon and ribavirin treatment," Journal of Virology, vol. 83, no. 21, pp. 11407-11411, 2009.

[76] G. Greub, B. Ledergerber, M. Battegay et al., "Clinical progression, survival, and immune recovery during antiretroviral therapy in patients with HIV-1 and hepatitis $\mathrm{C}$ virus coinfection: the swiss HIV cohort study," The Lancet, vol. 356, no. 9244, pp. 1800-1805, 2000.

[77] M. Potter, A. Odueyungbo, H. Yang, S. Saeed, and M. B. Klein, "Impact of hepatitis $\mathrm{C}$ viral replication on $\mathrm{CD} 4^{+} \mathrm{T}-$ lymphocyte progression in HIV-HCV coinfection before and 
after antiretroviral therapy," AIDS, vol. 24, no. 12, pp. 1857$1865,2010$.

[78] M. C. Villacres, S. F. Lacey, C. La Rosa et al., "Human immunodeficiency virus-infected patients receiving highly active antiretroviral therapy maintain activated CD8+ T cell subsets as a strong adaptive immune response to cytomegalovirus," Journal of Infectious Diseases, vol. 184, no. 3, pp. 256-267, 2001.

[79] J. M. Fletcher, M. Vukmanovic-Stejic, P. J. Dunne et al., "Cytomegalovirus-specific $\mathrm{CD} 4^{+} \mathrm{T}$ cells in healthy carriers are continuously driven to replicative exhaustion," Journal of Immunology, vol. 175, no. 12, pp. 8218-8225, 2005.

[80] L. Shen and R. F. Siliciano, "Viral reservoirs, residual viremia, and the potential of highly active antiretroviral therapy to eradicate HIV infection," Journal of Allergy and Clinical Immunology, vol. 122, no. 1, pp. 22-28, 2008.

[81] B. Joos, M. Fischer, H. Kuster et al., "HIV rebounds from latently infected cells, rather than from continuing low-level replication," Proceedings of the National Academy of Sciences of the United States of America, vol. 105, no. 43, pp. 1672516730, 2008.

[82] J. B. Dinoso, S. Y. Kim, A. M. Wiegand et al., "Treatment intensification does not reduce residual HIV-1 viremia in patients on highly active antiretroviral therapy," Proceedings of the National Academy of Sciences of the United States of America, vol. 106, no. 23, pp. 9403-9408, 2009.

[83] D. McMahon, J. Jones, A. Wiegand et al., "Short-course raltegravir intensification does not reduce persistent low-level viremia in patients with HIV-1 suppression during receipt of combination antiretroviral therapy," Clinical Infectious Diseases, vol. 50, no. 6, pp. 912-919, 2010.

[84] H. Hatano, T. L. Hayes, V. Dahl et al., "A randomized, controlled trial of raltegravir intensification in antiretroviraltreated, HIV-infected patients with a suboptimal CD4 ${ }^{+} \mathrm{T}$ cell response," Journal of Infectious Diseases, vol. 203, no. 7, pp. 960-968, 2011.

[85] R. T. Gandhi, L. Zheng, R. J. Bosch et al., "The effect of raltegravir intensification on low-level residual viremia in HIV-infected patients on antiretroviral therapy: a randomized controlled trial," PLoS Medicine, vol. 7, no. 8, Article ID e1000321, 2010

[86] F. Maldarelli, S. Palmer, M. S. King et al., "ART suppresses plasma HIV-1 RNA to a stable set point predicted by pretherapy viremia," PLoS Pathogens, vol. 3, no. 4, article e46, 2007.

[87] M. E. Sharkey, I. Teo, T. Greenough et al., "Persistence of episomal HIV-1 infection intermediates in patients on highly active anti-retroviral therapy," Nature Medicine, vol. 6, no. 1, pp. 76-81, 2000.

[88] M. J Buzón, M. Massanella, J. M. Llibre et al., "HIV-1 replication and immune dynamics are affected by raltegravir intensification of HAART-suppressed subjects," Nature Medicine, vol. 16, no. 4, pp. 460-465, 2010.

[89] N. Chomont, M. El-Far, P. Ancuta et al., "HIV reservoir size and persistence are driven by T cell survival and homeostatic proliferation," Nature Medicine, vol. 15, no. 8, pp. 893-900, 2009.

[90] M. J. Churchill, P. R. Gorry, D. Cowley et al., "Use of laser capture microdissection to detect integrated HIV-1 DNA in macrophages and astrocytes from autopsy brain tissues," Journal of NeuroVirology, vol. 12, no. 2, pp. 146-152, 2006.
[91] P. Gorry, D. Purcell, J. Howard, and D. McPhee, "Restricted HIV-1 infection of human astrocytes: potential role of nef in the regulation of virus replication," Journal of NeuroVirology, vol. 4, no. 4, pp. 377-386, 1998.

[92] P. J. Ellery, E. Tippett, Y. L. Chiu et al., "The CD16+ monocyte subset is more permissive to infection and preferentially harbors HIV-1 in vivo," Journal of Immunology, vol. 178, no. 10, pp. 6581-6589, 2007.

[93] J. Dai, L. M. Agosto, C. Baytop et al., "Human immunodeficiency virus integrates directly into naïve resting $\mathrm{CD} 4^{+} \mathrm{T}$ cells but enters naïve cells less efficiently than memory cells," Journal of Virology, vol. 83, no. 9, pp. 4528-4537, 2009.

[94] F. Wightman, A. Solomon, G. Khoury et al., "Both $\mathrm{CD} 31^{+}$and $\mathrm{CD} 31^{-}$naive $\mathrm{CD} 4^{+} \mathrm{T}$ cells are persistent HIV type 1 -infected reservoirs in individuals receiving antiretroviral therapy," Journal of Infectious Diseases, vol. 202, no. 11, pp. 1738-1748, 2010.

[95] D. G. Brooks, S. G. Kitchen, C. M. R. Kitchen, D. D. Scripture-Adams, and J. A. Zack, "Generation of HIV latency during thymopoiesis," Nature Medicine, vol. 7, no. 4, pp. 459464, 2001.

[96] T. W. Chun, D. C. Nickle, J. S. Justement et al., "Persistence of HIV in gut-associated lymphoid tissue despite long-term antiretroviral therapy," Journal of Infectious Diseases, vol. 197, no. 5, pp. 714-720, 2008.

[97] C. K. Petito, "Human immunodeficiency virus type 1 compartmentalization in the central nervous system," Journal of NeuroVirology, vol. 10, no. 1, pp. 21-24, 2004.

[98] P. M. Sheth, C. Kovacs, K. S. Kemal et al., "Persistent HIV RNA shedding in semen despite effective antiretroviral therapy," AIDS, vol. 23, no. 15, pp. 2050-2054, 2009.

[99] G. Nunnari, D. Leto, J. Sullivan et al., "Seminal reservoirs during an HIV type 1 eradication trial," AIDS Research and Human Retroviruses, vol. 21, no. 9, pp. 768-775, 2005.

[100] G. Nunnari, J. Sullivan, Y. Xu et al., "HIV type 1 cervicovaginal reservoirs in the era of HAART," AIDS Research and Human Retroviruses, vol. 21, no. 8, pp. 714-718, 2005.

[101] J. D. Siliciano, J. Kajdas, D. Finzi et al., "Long-term follow-up studies confirm the stability of the latent reservoir for HIV-1 in resting $\mathrm{CD}^{+} \mathrm{T}$ cells," Nature Medicine, vol. 9, no. 6, pp. 727-728, 2003.

[102] K. K. Koelsch, L. Liu, R. Haubrich et al., "Dynamics of total, linear nonintegrated, and integrated HIV-1 DNA in vivo and in vitro," Journal of Infectious Diseases, vol. 197, no. 3, pp. 411-419, 2008.

[103] A. O. Pasternak, S. Jurriaans, M. Bakker, J. M. Prins, B. Berkhout, and V. V. Lukashov, "Cellular levels of HIV unspliced RNA from patients on combination antiretroviral therapy with undetectable plasma viremia predict the therapy outcome," PLoS One, vol. 4, no. 12, Article ID e8490, 2009.

[104] G. d'Ettorre, M. Paiardini, L. Zaffiri et al., "HIV persistence in the gut mucosa of HIV-infected subjects undergoing antiretroviral therapy correlates with immune activation and increased levels of LPS," Current HIV Research, vol. 9, no. 3, pp. 148-153, 2011.

[105] J. Neuhaus, D. R. Jacobs, J. V. Baker et al., "Markers of inflammation, coagulation, and renal function are elevated in adults with HIV infection," Journal of Infectious Diseases, vol. 201, no. 12, pp. 1788-1795, 2010.

[106] L. H. Kuller, R. Tracy, W. Belloso et al., "Inflammatory and coagulation biomarkers and mortality in patients with HIV infection," PLoS Medicine, vol. 5, no. 10, article e203, 2008. 
[107] A. Eastburn, R. Scherzer, A. R. Zolopa et al., "Association of low level viremia with inflammation and mortality in HIVinfected adults," PLoS One, vol. 6, no. 11, Article ID e26320, 2011.

[108] M. J. Mugavero, S. Napravnik, S. R. Cole et al., "Viremia copy-years predicts mortality among treatment-naive HIVinfected patients initiating antiretroviral therapy," Clinical Infectious Diseases, vol. 53, no. 9, pp. 927-935, 2011.

[109] S. R. Cole, S. Napravnik, M. J. Mugavero, B. Lau, J. Eron, and M. S. Saag, "Copy-years viremia as a measure of cumulative human immunodeficiency virus viral burden," American Journal of Epidemiology, vol. 171, no. 2, pp. 198-205, 2010.

[110] C. Argyropoulos and A. Mouzaki, "Immunosuppressive drugs in HIV disease," Current Topics in Medicinal Chemistry, vol. 6, no. 16, pp. 1769-1789, 2006.

[111] T. Wilkin, C. Lalama, A. R. Tenorio et al., "Maraviroc intensification for suboptimal $\mathrm{CD}^{+}$cell response despite sustained virologic suppression: ATCG 5256," in Proceedings of the 17th Conference on Retroviruses and Opportunistic Infections, San Francisco, Calif, USA, February 2010, Abstract 285.

[112] C. Gutierrez, L. Diaz, B. Hernandez-Novoa et al., "Effect of the intensification with a CCR5 antagonist on the decay of the HIV-1 latent reservoir and residual viremia," in Proceedings of the 17th Conference on Retroviruses and Opportunistic Infections, San Francisco, Calif, USA, February 2010, Abstract 284

[113] J. Sierra-Madero, G. Di Perri, R. Wood et al., "Efficacy and safety of maraviroc versus efavirenz, both with zidovudine/lamivudine: 96-week results from the MERIT study," HIV Clinical Trials, vol. 11, no. 3, pp. 125-132, 2010.

[114] S. De Wit, M. Delforge, C. V. Necsoi, and N. Clumeck, "Downregulation of CD38 activation markers by atorvastatin in HIV patients with undetectable viral load," AIDS, vol. 25, no. 10, pp. 1332-1333, 2011.

[115] E. Czeslick, A. Struppert, A. Simm, and A. Sablotzki, “E5564 (Eritoran) inhibits lipopolysaccharide-induced cytokine production in human blood monocytes," Inflammation Research, vol. 55, no. 11, pp. 511-515, 2006.

[116] N. C. Connolly, S. A. Riddler, and C. R. Rinaldo, "Proinflammatory cytokines in HIV disease-a review and rationale for new therapeutic approaches," AIDS Reviews, vol. 7, no. 3, pp. 168-180, 2005.

[117] S. Piconi, S. Parisotto, G. Rizzardini et al., "Hydroxychloroquine drastically reduces immune activation in HIV-infected, antiretroviral therapy-treated immunologic nonresponders," Blood, vol. 118, no. 12, pp. 3263-3272, 2011.

[118] R. T. Davey, R. L. Murphy, F. M. Graziano et al., "Immunologic and virologic effects of subcutaneous interleukin 2 in combination with antiretroviral therapy: a randomized controlled trial," JAMA, vol. 284, no. 2, pp. 183-189, 2000.

[119] C. Katlama, G. Carcelain, C. Duvivier et al., "Interleukin2 accelerates CD4 cell reconstitution in HIV-infected patients with severe immunosuppression despite highly active antiretroviral therapy: the ILSTIM study-ANRS 082," AIDS, vol. 16, no. 15, pp. 2027-2034, 2002.

[120] Y. Levy, C. Durier, R. Krzysiek et al., "Effects of interleukin-2 therapy combined with highly active antiretroviral therapy on immune restoration in HIV-1 infection: a randomized controlled trial," AIDS, vol. 17, no. 3, pp. 343-351, 2003.

[121] R. Paredes, J. C. López Bernaldo De Quirós, E. FernándezCruz, B. Clotet, and H. C. Lane, "The potential role of interleukin-2 in patients with HIV infection," AIDS Reviews, vol. 4, no. 1, pp. 36-40, 2002.
[122] L. Caggiari, S. Zanussi, M. T. Bortolin et al., "Effects of therapy with highly active anti-retroviral therapy (HAART) and IL-2 on $\mathrm{CD}^{+}$and $\mathrm{CD}^{+}$lymphocyte apoptosis in HIV+ patients," Clinical and Experimental Immunology, vol. 120, no. 1, pp. 101-106, 2000.

[123] W. Zou, A. Fousst, C. Capitant et al., "Acute activation of $\mathrm{CD}^{+} \mathrm{T}$ lymphocytes in interleukin-2-treated HIVinfected patients," Journal of Acquired Immune Deficiency Syndromes and Human Retrovirology, vol. 22, no. 1, pp. 3138, 1999.

[124] J. Kutza, M. P. Hayes, and K. A. Clouse, "Interleukin2 inhibits HIV-1 replication in human macrophages by modulating expression of CD4 and CC-chemokine receptor5," AIDS, vol. 12, no. 8, pp. F59-F64, 1998.

[125] D. Abrams, Y. Lévy, M. H. Losso et al., "Interleukin-2 therapy in patients with HIV infection," The New England Journal of Medicine, vol. 361, no. 16, pp. 1548-1559, 2009.

[126] S. Emery, D. I. Abrams, D. A. Cooper et al., "The Evaluation of Subcutaneous Proleukin $\mathbb{R}$ (interleukin-2) in a Randomized International Trial: rationale, design, and methods of ESPRIT," Controlled Clinical Trials, vol. 23, no. 2, pp. 198220, 2002.

[127] Y. Levy, C. Lacabaratz, L. Weiss et al., "Enhanced T cell recovery in HIV-1-infected adults through IL-7 treatment," The Journal of Clinical Investigation, vol. 119, no. 4, pp. 997$1007,2009$.

[128] C. L. Mackall, T. J. Fry, C. Bare, P. Morgan, A. Galbraith, and R. E. Gress, "IL-7 increases both thymic-dependent and thymic-independent T-cell regeneration after bone marrow transplantation," Blood, vol. 97, no. 5, pp. 1491-1497, 2001.

[129] A. Oliva, A. L. Kinter, M. Vaccarezza et al., "Natural killer cells from human immunodeficiency virus (HIV)-infected individuals are an important source of CC-chemokines and suppress HIV-1 entry and replication in vitro," The Journal of Clinical Investigation, vol. 102, no. 1, pp. 223-231, 1998.

[130] M. Prlic, B. R. Blazar, M. A. Farrar, and S. C. Jameson, "In vivo survival and homeostatic proliferation of natural killer cells," Journal of Experimental Medicine, vol. 197, no. 8, pp. 967-976, 2003.

[131] G. D’Ettorre, M. Andreotti, G. Ceccarelli et al., "The role of IL-15 in challenging Acquired Immunodeficiency Syndrome," Cytokine, vol. 57, no. 1, pp. 54-60, 2012.

[132] G. D'Ettorre, M. Andreotti, M. Carnevalini et al., "Interleukin-15 enhances the secretion of IFN- $\gamma$ and CC chemokines by natural killer cells from HIV viremic and aviremic patients," Immunology Letters, vol. 103, no. 2, pp. 192-195, 2006

[133] M. Tarkowski, L. Ferraris, S. Martone et al., "Expression of interleukin-15 and interleukin-15R $\alpha$ in monocytes of HIV type 1-infected patients with different courses of disease progression," AIDS Research and Human Retroviruses. In press.

[134] I. Sereti, R. M. Dunham, J. Spritzler et al., "IL-7 administration drives $\mathrm{T}$ cell-cycle entry and expansion in HIV-1 infection," Blood, vol. 113, no. 25, pp. 6304-6314, 2009.

[135] F. X. Wang, Y. Xu, J. Sullivan et al., "IL-7 is a potent and proviral strain-specific inducer of latent HIV-1 cellular reservoirs of infected individuals on virally suppressive HAART," The Journal of Clinical Investigation, vol. 115, no. 1, pp. 128-137, 2005. 
[136] C. Vandergeeten, S. DaFonseca, R. Fromentin et al., "Differential impact of IL-7 and IL-15 on HIV reservoir persistence," in Proceedings of the 5th International Workshop on HIV Persistence during Therapy, St Maarten, West Indies, December 2011, Abstract 29.

[137] N. M. Archin, K. S. Keedy, A. Espeseth, H. Dang, D. J. Hazuda, and D. M. Margolis, "Expression of latent human immunodeficiency type 1 is induced by novel and selective histone deacetylase inhibitors," AIDS, vol. 23, no. 14, pp. 1799-1806, 2009.

[138] L. Ylisastigui, N. M. Archin, G. Lehrman, R. J. Bosch, and D. M. Margolis, "Coaxing HIV-1 from resting CD4 T cells: histone deacetylase inhibition allows latent viral expression," AIDS, vol. 18, no. 8, pp. 1101-1108, 2004.

[139] N. M. Archin, J. J. Eron, S. Palmer et al., "Valproic acid without intensified antiviral therapy has limited impact on persistent HIV infection of resting $\mathrm{CD}^{+}{ }^{+} \mathrm{T}$ cells," AIDS, vol. 22, no. 10, pp. 1131-1135, 2008.

[140] N. Sagot-Lerolle, A. Lamine, M. L. Chaix et al., "Prolonged valproic acid treatment does not reduce the size of latent HIV reservoir," AIDS, vol. 22, no. 10, pp. 1125-1129, 2008.

[141] J. D. Siliciano, J. Lai, M. Callender et al., "Stability of the latent reservoir for HIV-1 in patients receiving valproic acid," Journal of Infectious Diseases, vol. 195, no. 6, pp. 833-836, 2007.

[142] J. Kulkosky, D. M. Culnan, J. Roman et al., "Prostratin: activation of latent HIV-1 expression suggests a potential inductive adjuvant therapy for HAART," Blood, vol. 98, no. 10, pp. 3006-3015, 2001.

[143] S. Reuse, M. Calao, K. Kabeya et al., "Synergistic activation of HIV-1 expression by deacetylase inhibitors and prostratin: implications for treatment of latent infection," PLoS One, vol. 4, no. 6, Article ID e6093, 2009.

[144] R. Mehla, S. Bivalkar-Mehla, R. Zhang et al., "Bryostatin modulates latent HIV-1 infection via PKC and AMPK signaling but inhibits acute infection in a receptor independent manner," PLoS One, vol. 5, no. 6, Article ID e11160, 2010.

[145] J. Blazkova, K. Trejbalova, F. Gondois-Rey et al., "CpG methylation controls reactivation of HIV from latency," PLoS Pathogens, vol. 5, no. 8, Article ID e1000554, 2009.

[146] S. E. Kauder, A. Bosque, A. Lindqvist, V. Planelles, and E. Verdin, "Epigenetic regulation of HIV-1 latency by cytosine methylation," PLoS Pathogens, vol. 5, no. 6, Article ID e1000495, 2009.

[147] M. G. Lewis, S. Dafonseca, N. Chomont et al., "Gold drug auranofin restricts the viral reservoir in the monkey AIDS model and induces containment of viral load following ART suspension," AIDS, vol. 25, no. 11, pp. 1347-1356, 2011.

[148] B. Ensoli, S. Bellino, A. Tripiciano et al., "Therapeutic immunization with hiv-1 tat reduces immune activation and loss of regulatory t-cells and improves immune function in subjects on HAART," PLoS One, vol. 5, no. 11, Article ID e13540, 2010.

[149] B. Autran, R. L. Murphy, D. Costagliola et al., "Greater viral rebound and reduced time to resume antiretroviral therapy after therapeutic immunization with the ALVACHIV vaccine (vCP1452)," AIDS, vol. 22, no. 11, pp. 13131322, 2008. 


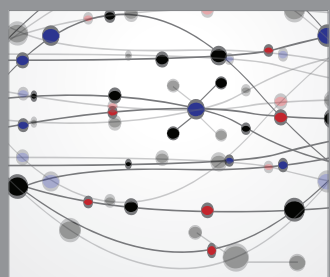

The Scientific World Journal
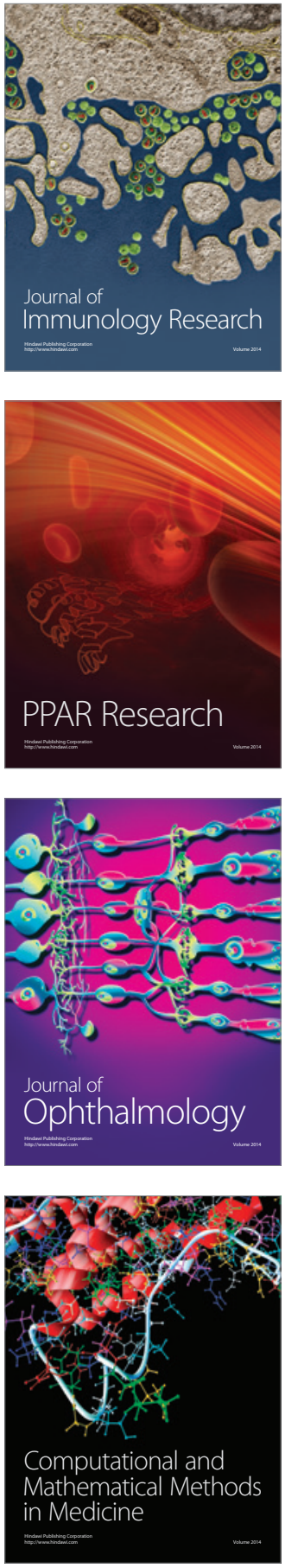

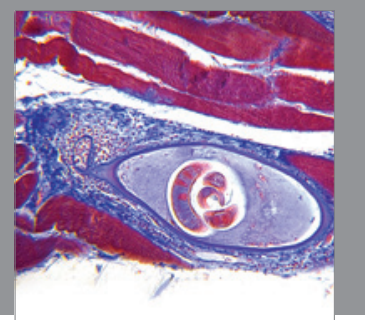

Gastroenterology

Research and Practice
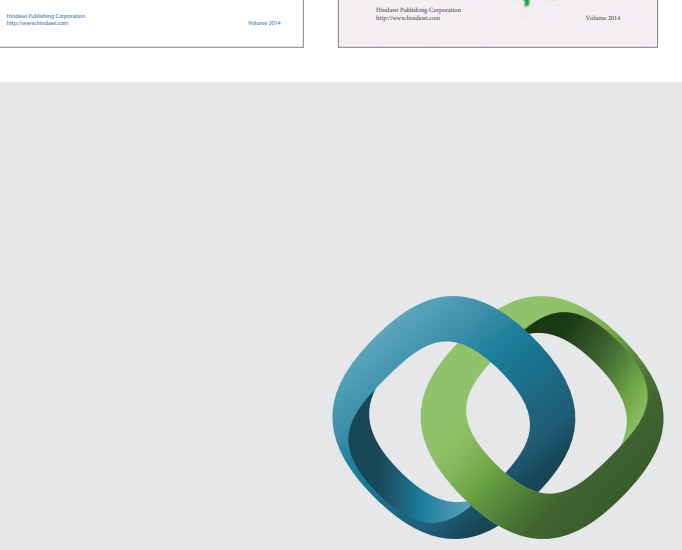

\section{Hindawi}

Submit your manuscripts at

http://www.hindawi.com
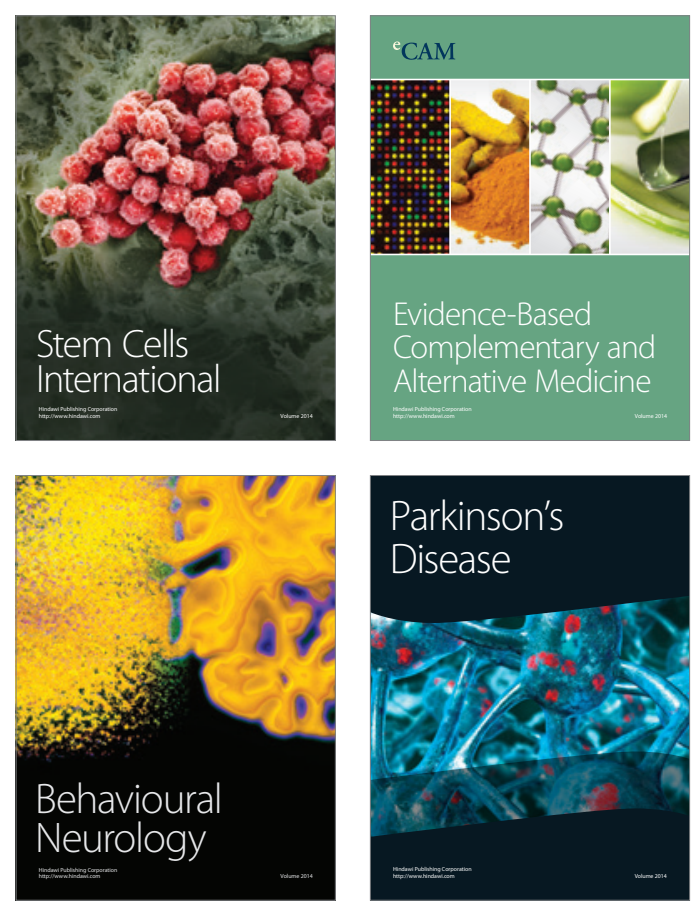

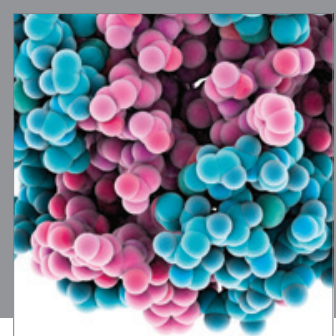

Journal of
Diabetes Research

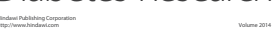

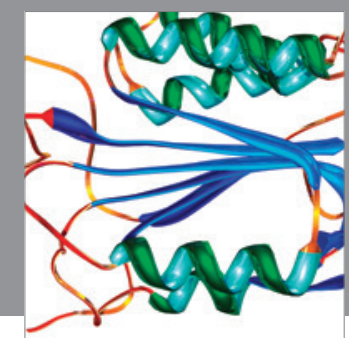

Disease Markers
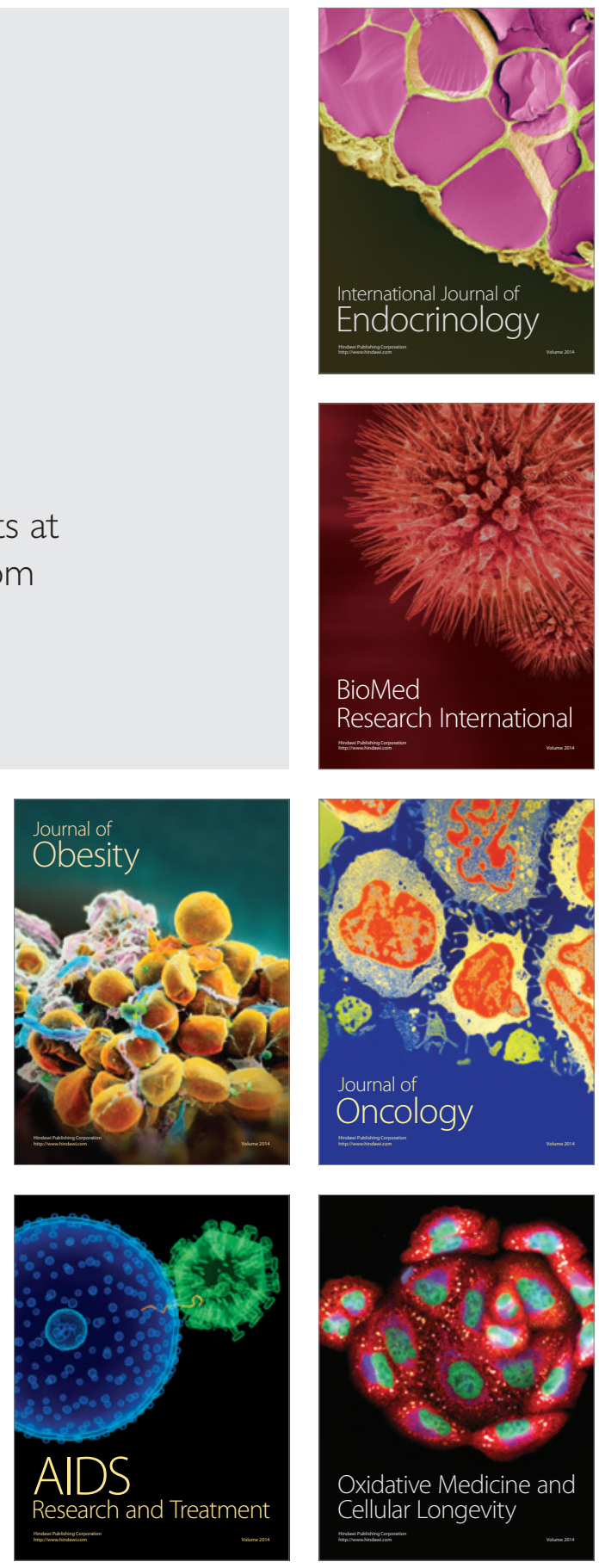